\title{
Updates in Congenital Heart Disease: Can Outcomes Improve?
}

\author{
Gerard R. Martin, MD ${ }^{1}$ Russell R. Cross, MD ${ }^{1} \quad$ Lisa A. Hom, RN Esq ${ }^{1} \quad$ Darren Klugman, MD ${ }^{1,2}$ \\ ${ }^{1}$ Division of Cardiology, Children's National Heart Institute, George \\ Washington University School of Medicine, Washington, District of \\ Columbia \\ 2 Division of Cardiac Critical Care Medicine, Children's National Heart \\ Institute, George Washington University School of Medicine, \\ Washington, District of Columbia \\ Address for correspondence Gerard R. Martin, MD, 111 Michigan \\ Avenue, NW, Washington DC 20010 (e-mail: gmartin@cnmc.org). \\ Am J Perinatol 2019;36(suppl S2):S22-S28.
}

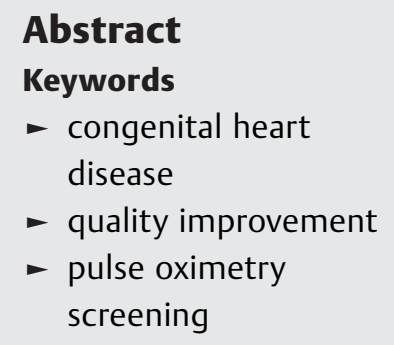

Congenital heart disease (CHD) is the most common birth defect impacting nearly 1 out of every 100 live births. ${ }^{1}$ Due to numerous medical and surgical advances in the management of CHD, early and late survival has improved in the current era. ${ }^{2}$ Despite these advances, CHD remains the most common cause of death from congenital birth defects in the first year of life. ${ }^{3}$ Late detection of critical CHD, incomplete delineation of complex anatomy, and gaps in the standardization of care delivery are potential contributors to the morbidity and mortality in CHD. This article will discuss the impact of pulse oximetry screening for critical CHD, describe the contributions of advanced cardiac imaging in the neonate with CHD, and show the growing importance of quality improvement and safety programs in the cardiac intensive care unit (CICU).

\section{Improved Detection of Critical Congenital Heart Disease}

The late detection of critical CHD has been recognized as a contributor to the early morbidity and mortality associated with CHD. ${ }^{4,5}$ Earlier critical CHD diagnosis in a New Zealand study showed $16 \%$ mortality compared with $27 \%$ mortality for infants with critical CHD who received a late diagnosis. ${ }^{6}$ Despite improvements in the prenatal detection of CHD, the rates of prenatal detection have shown significant variation between hospitals and disappointing national detection rates for transposition of the great arteries (37\%) and coarctation of the aorta (34\%). ${ }^{7}$ Because of the difficulty in detecting mild and even moderate cyanosis, physical examination has also shown only a $50 \%$ likelihood of detecting critical CHD.

National recommendations for pulse oximetry screening for critical CHD are becoming more common (-Table $\mathbf{1}$ ). A Cochrane analysis of pulse oximetry screening for critical CHD showed moderate sensitivity and high specificity. ${ }^{8}$ In the United States, newborn screening has been adopted in all 50 states and the District of Columbia. ${ }^{9}$ A recent study has shown the association of state implementation of pulse oximetry screening policies with a significant reduction in early infant cardiac deaths. ${ }^{10}$ States with legislation mandating newborn screening achieved a 33\% reduction in early cardiac deaths due to CCHD compared with states with no policy or a nonmandatory policy. This reduction in mortality resulted in approximately 120 lives saved (95\% confidence interval [CI]: $38-181$ ) per year and an additional $21 \%$ reduction in other/unspecified CHD deaths in states, equivalent to another 117 lives saved (95\% CI: 38-185) per year. Identifying infants with critical CHD early allows them to receive timely interventions, such as cardiovascular surgical repair or cardiac catheterization, and dramatically improves their chances of avoiding not only death but also morbidity associated with heart failure. Improvements in screening

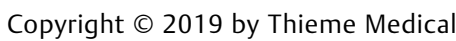
Publishers, Inc., 333 Seventh Avenue, New York, NY 10001, USA. Tel: +1(212) 584-4662. ISSN 0735-1631. 
Table 1 Global critical congenital heart disease screening implementation

\begin{tabular}{|c|c|c|c|c|}
\hline $\begin{array}{l}\text { National recommendation } \\
\text { to } \text { screen }^{\mathrm{a}}\end{array}$ & $\begin{array}{l}\text { More than } 90 \% \text { of } \\
\text { births screened }\end{array}$ & \multicolumn{2}{|c|}{$\begin{array}{l}\text { Implementation underway including } \\
\text { multicenter studies and pilot } \\
\text { programs }\end{array}$} & Interest in screening \\
\hline $\begin{array}{l}\text { Argentina } \\
\text { Brazil } \\
\text { Canada } \\
\text { China } \\
\text { Ireland } \\
\text { Mongolia } \\
\text { Spain } \\
\text { Saudi Arabia } \\
\text { Sri Lanka } \\
\text { Germany } \\
\text { Norway } \\
\text { Switzerland } \\
\text { Poland } \\
\text { United States } \\
\text { United Arab Emirates }\end{array}$ & $\begin{array}{l}\text { Costa Rica } \\
\text { Finland } \\
\text { Georgia } \\
\text { Malta } \\
\text { Slovakia } \\
\text { Sweden }\end{array}$ & $\begin{array}{l}\text { Australia } \\
\text { Azerbaijan } \\
\text { Bahrain } \\
\text { Bangladesh } \\
\text { Bolivia } \\
\text { Bosnia } \\
\text { BulgariaMexico } \\
\text { Colombia } \\
\text { Denmark } \\
\text { Ecuador } \\
\text { Ethiopia } \\
\text { France } \\
\text { Guatemala } \\
\text { Honduras } \\
\text { India } \\
\text { Indonesia } \\
\text { Iran } \\
\text { Israel } \\
\text { Italy } \\
\text { Kuwait } \\
\text { Latvia }\end{array}$ & $\begin{array}{l}\text { Malawi } \\
\text { Malaysia } \\
\text { Morocco } \\
\text { The Netherlands } \\
\text { Nepal } \\
\text { New Zealand } \\
\text { Nigeria } \\
\text { Pakistan } \\
\text { Paraguay } \\
\text { Peru } \\
\text { Philippines } \\
\text { Portugal } \\
\text { Qatar } \\
\text { Russia } \\
\text { Slovenia } \\
\text { South Africa } \\
\text { Taiwan } \\
\text { Thailand } \\
\text { Tibet } \\
\text { Turkey } \\
\text { Ukraine } \\
\text { United Kingdom } \\
\text { Uruguay } \\
\text { Vietnam }\end{array}$ & $\begin{array}{l}\text { Austria } \\
\text { Chile } \\
\text { Croatia } \\
\text { Cuba } \\
\text { Egypt } \\
\text { Estonia } \\
\text { Greece } \\
\text { Japan } \\
\text { Kenya } \\
\text { Lithuania } \\
\text { Romania } \\
\text { Samoan Islands } \\
\text { Singapore } \\
\text { Tunisia } \\
\text { Zambia }\end{array}$ \\
\hline
\end{tabular}

${ }^{a}$ National recommendation to screen includes countries where a government policy or a professional medical society recommends or requires screening for critical congenital heart disease.

during the neonatal phase, whether through pulse oximetry screening, prenatal ultrasound and postnatal exam, can all impact early identification of this disease.

\section{Advanced Cardiac Imaging in the Neonate with Congenital Heart Disease}

The development of two-dimensional echocardiography in the 1960s revolutionized the approach to the newborn with CHD and has become the mainstay for diagnosis and management of these patients. However, echocardiography does have restrictions, such as the need to acquire images from certain "anatomic windows," difficulty demonstrating certain three-dimensional relationships, and limited ability to provide hemodynamic information. Over the past three decades, advancement in alternative imaging modalities, particularly cardiac magnetic resonance imaging (CMR) and computed tomography (CT), have continued to improve and revolutionize the approach to the diagnostic and hemodynamic evaluation of patients with CHD. ${ }^{11-13}$ Efforts have also progressed through multiple societies and organizations to develop guidelines for the appropriate use of advanced cardiac imaging in this patient population. ${ }^{14-16}$ As advancements continue and indications become more well defined, newborns and infants with CHD benefit from advanced cardiac imaging techniques to improve diagnostic accuracy and provide a broader spectrum of noninvasive hemodynamic evaluation, while at the same time decreasing safety concerns associated with these techniques. ${ }^{17}$
Advantages of advanced cardiac imaging vary based on the modality, but both CMR and CT are noninvasive and provide images with large field of view that is unconstrained by acquisition windows or imaging planes. Both techniques have the ability to provide functional information (chamber volume, stroke volume, ejection fraction) of the heart based on acquired three-dimensional data that is not reliant on modeling or anatomic assumptions. Likewise, both modalities can provide information on myocardial perfusion and tissue viability. CMR is particularly advantageous because it is radiation free, provides excellent tissue contrast and temporal resolution, allows for blood flow analysis (velocity and volume quantification), as well as tissue characterization. An additional benefit of CMR is that significant diagnostic information can be obtained without the use of contrast agents. CT, on the other hand, provides very high spatial resolution and can be performed very quickly, albeit with the need for intravascular contrast in most cases. Cardiac CT does utilize radiation, but advancements in scanner technology have drastically reduced dosages such that modern cardiac CT scans can be obtained with similar or less radiation than is required for a typical chest X-ray. Both advanced cardiac imaging modalities also have traditionally shared some common disadvantages, namely, being intolerant to patient motion, requiring sedation or breath holds in many cases, and being difficult to perform in patients with cardiac arrhythmias. The techniques are also technically complex, requiring specialized equipment as well as expertise in the field. Nonetheless, advanced cardiac imaging has 
significantly strengthened the noninvasive diagnostic capabilities for cardiovascular imaging over the past two decades. Developments such as motion-corrected imaging sequences, rapid imaging scanners and sequences, neonatal-specific MRI coils, and the use of novel clinical approaches such as "feed and sleep" imaging have all contributed to the increased applicability of CMR and cardiac CT in management of the neonate with CHD. ${ }^{18}$

Although echocardiography is able to provide excellent diagnostic details in most newborns with CHD, there are questions that can sometimes remain after a study is performed. In some instances, questions regarding the threedimensional relationship of heart structures can remain, such as the ventriculoarterial connection relationship in complex heart disease or anatomic details of atrioventricular valves in the setting of questionable ventricular hypoplasia. These details can impact the approach to intervention and are important to obtain before repair is undertaken (-Fig.1).
Echocardiography can also sometimes leave questions regarding anatomic details of vascular anatomy or its relationship to other structures within the chest. Advanced cardiac imaging plays an important role in the evaluation of vascular rings (-Fig. 2), determining the presence or absence of aortopulmonary collaterals in certain diseases, visualizing details of venous anatomy related to heterotaxy syndrome, and defining structural details of anomalous pulmonary veins (-Fig. 3). Additionally, echocardiography is limited in its ability to provide some details that impact hemodynamics and physiology. For example, volume quantification in the setting of ventricular hypoplasia to determine adequacy for a biventricular repair, or measurement of pulmonary-to-systemic blood flow ratio or differential pulmonary blood flow in certain disease states can guide the management approach ( - Fig. 4). CMR, in particular, can be an invaluable tool for defining the nature of intracardiac or thoracic masses due to its ability to provide tissue

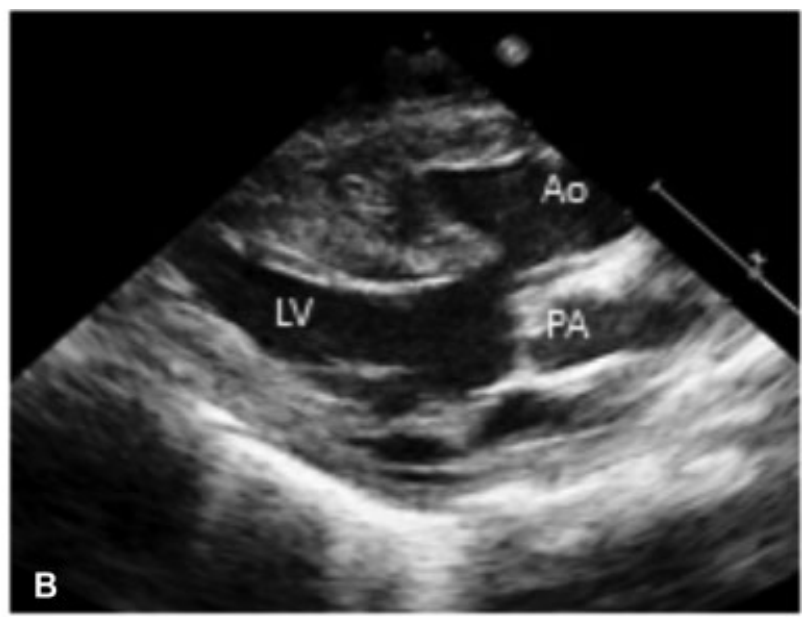

A
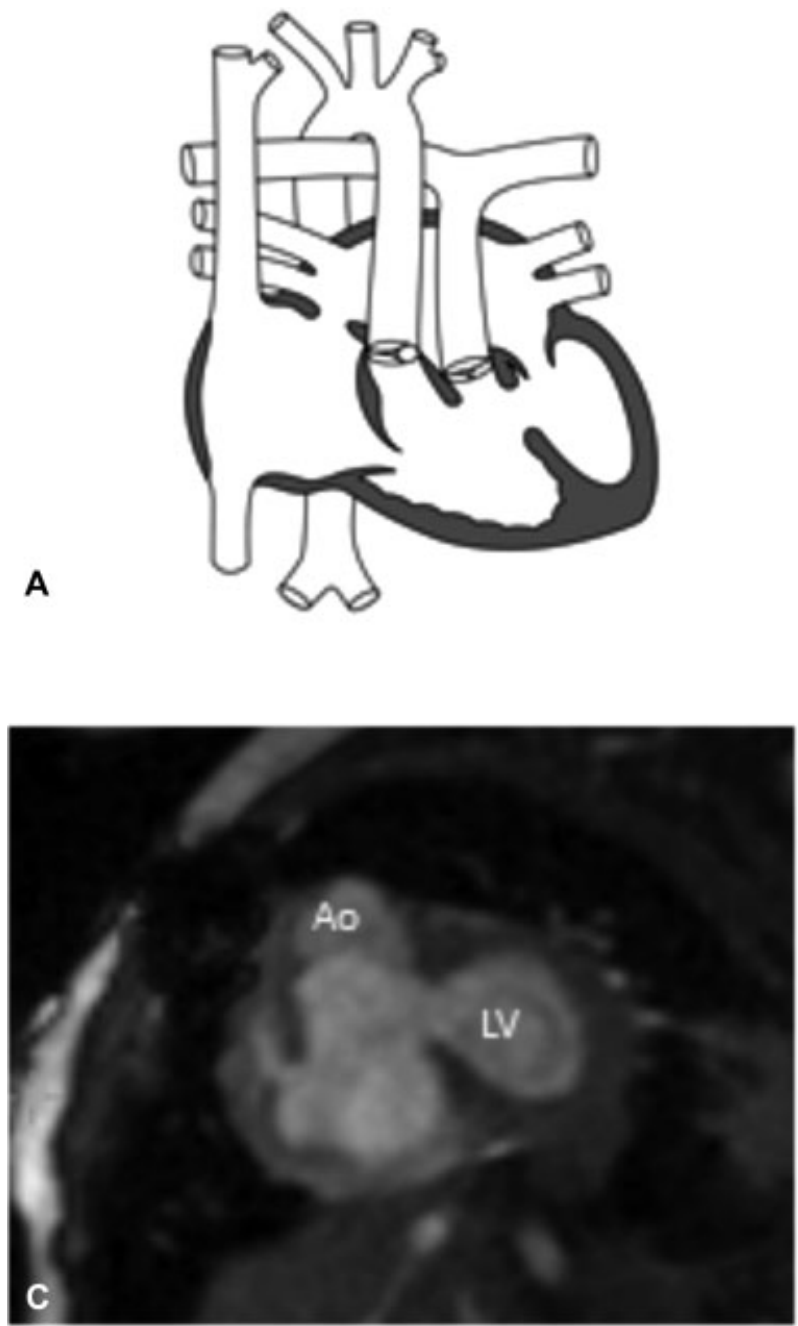

Fig. 1 Newborn with complex congenital heart disease consisting of transposition of the great arteries and a VSD (adapted from Charles E Mullins, David C Mayer. Congenital Heart Disease: A Diagrammatic Atlas. New York; 1988) (A). After the initial echocardiogram (B), it was unclear whether repair could be performed by baffling the VSD to the aorta or if an arterial switch operation would be required. Cardiac MRI (C) demonstrated a suitable pathway for baffling the left ventricular blood flow through the defect to the aorta, such that an arterial switch was not required. The patient underwent a "Rastelli-type" operation with placement of a right ventricle to pulmonary artery conduit and baffle closure of the VSD to the aorta (adapted from Charles E Mullins, David C Mayer. Congenital Heart Disease: A Diagrammatic Atlas. New York; 1988) (D). MRI, magnetic resonance imaging; VSD, ventricular septal defect. 

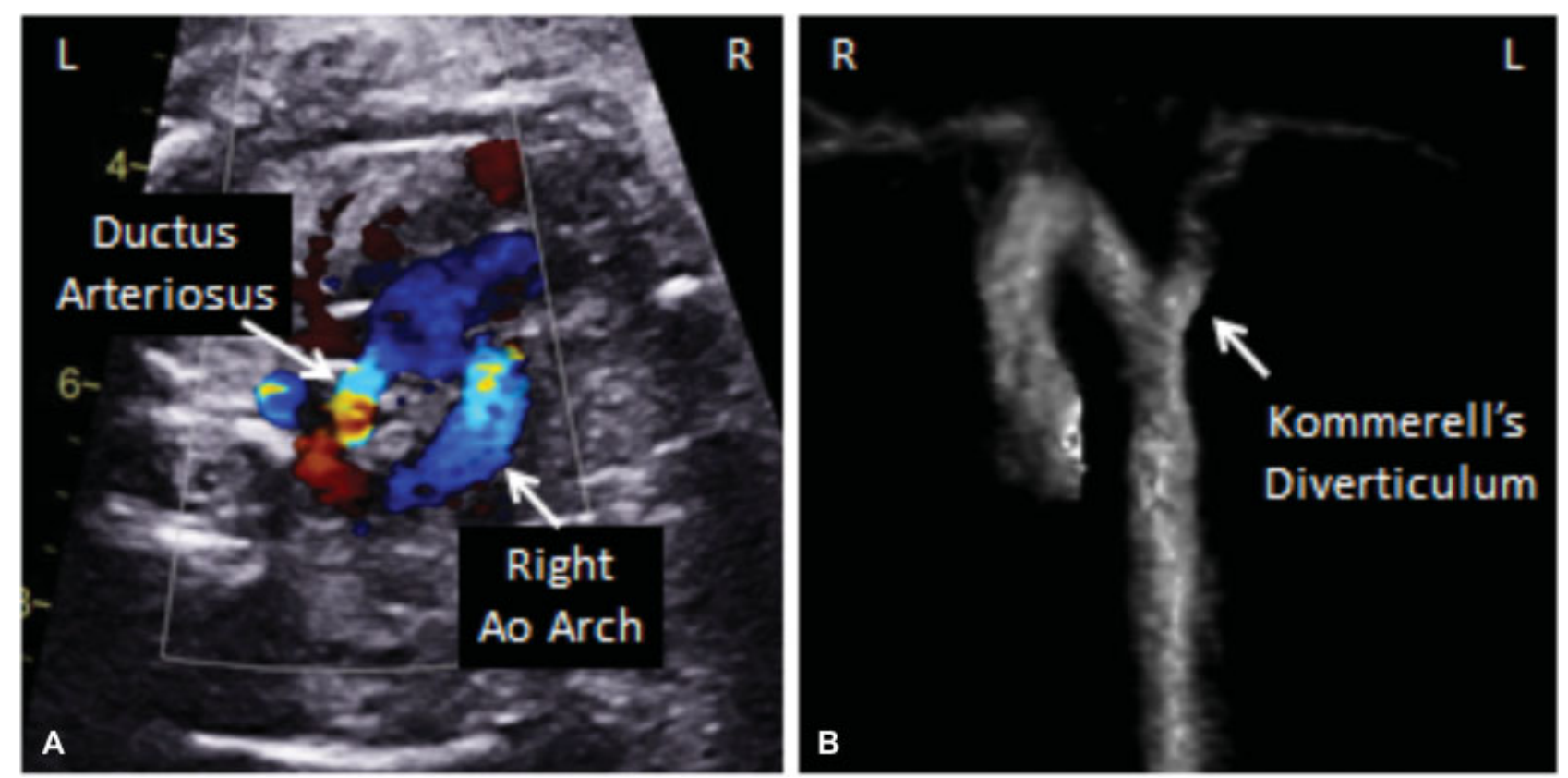

Fig. 2 Fetal echocardiogram demonstrated probable right aortic arch with a left-sided ductus arteriosus (A). Postnatal cardiac MRI performed at 6 weeks of age verified the presence of a right aortic arch with an aberrant left subclavian artery and Kommerell's diverticulum, confirming the presence of a vascular ring (B). The confirmatory imaging was accomplished without sedation using a feed and bundle technique and did not expose the newborn to ionizing radiation. MRI, magnetic resonance imaging.

characterization information which can guide medical decision making (-Fig. 5).

Advanced cardiac imaging currently plays an important role in answering these questions in a noninvasive and reliable manner, and continued technical advancements will only strengthen the ability to provide detailed anatomic and functional imaging while minimizing or eliminating safety concerns associated with sedation, contrast, and radiation exposure.

\section{Quality Improvement and Safety Programs in the Cardiac Intensive Care Unit}

Patient care in the CICU is increasingly complex and requires a well-coordinated team with several disciplines including intensive care physicians, anesthesiologists, nursing, cardiologists, dieticians, social workers, perfusionists, respiratory technicians, fellows, and surgeons. Care coordination between these providers is essential to optimize care delivery and outcomes.

With growing emphasis on public reporting, data transparency, and patient advocacy, understanding ways to improve care coordination and outcomes is essential. Quality improvement science is the systematic study of processes and systems involved in care delivery to optimize outcomes. Principles of quality improvement can be applied to a single center and are also well suited to multi-institutional collaboratives. To optimize the success of this work, multidisciplinary collaboration is also essential.

Randomized controlled trials and large multicenter drug trials are becoming less common and more difficult to conduct due to cost, regulatory oversight and inherent heterogeneity of CHD. Significant variation in outcomes remains across hospitals, and there is a need to benchmark quality and reduce morbidity and mortality. Because of the limitations of large multicenter trials, quality improvement collaboratives and large database/registry studies are important platforms. Large databases such as the Society of Thoracic Surgeons, Pediatric Cardiac Critical Care Consortium (PC4), and National Pediatric Cardiology Quality Improvement Collaborative (NPCQIC) are examples of population level data registries which allow for the compilation of large amounts of patient demographic, care, and outcomes data. The PC $4^{19}$ began in 2009 and sought to improve outcomes for patients with critical pediatric and CHD using continuous quality improvement through data analysis and collaborative learning.

Further, PC4 and NPCQIC are focused on quality improvement and outcomes, and recent studies have demonstrated the potential impact of conducting research and quality improvement utilizing these large multicenter registries. $^{20,21}$ The NPCQIC is a multicenter collaborative focused on reducing mortality and improving weight gain between the first- and second-stage palliative procedures in patients with hypoplastic left heart syndrome. Anderson et al demonstrated a $44 \%$ reduction in mortality and a $28 \%$ reduction in interstage growth failure through the NPCQIC with particular focus on "all teach, all learn" information and data sharing as well as parental engagement. ${ }^{20}$ The success of registries such as PC4 and NPCQIC clearly highlights distinct benefits of timely feedback on performance and outcomes, maintaining and tracking practice variation and linking these to outcomes, and importantly to facilitate wide-scale learning on rare diagnosis, such as hypoplastic left heart syndrome. 


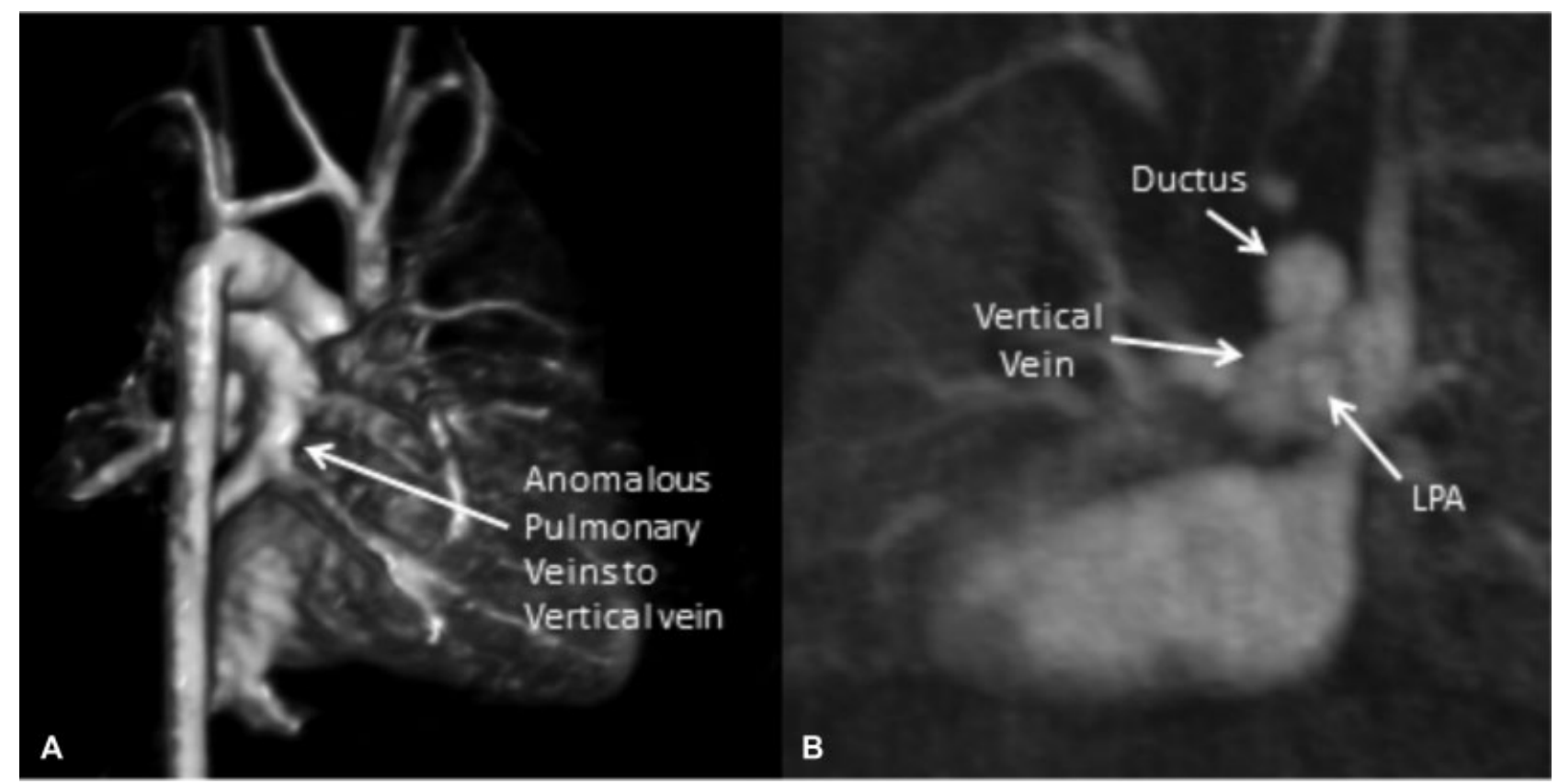

Fig. 3 Cardiac MRI performed in a 4-day-old, 2-kg newborn with hypoplastic left heart syndrome for whom ductal stenting was considered. The infant also had total anomalous pulmonary venous return with a vertical vein to a left superior vena cava, raising concern of how ductal stenting could affect the venous return. MRI with contrast verified the anatomy $(A)$ and demonstrated that ductal stenting would potentially cause compression of the vertical vein as it passed between the ductus arteriosus and the left pulmonary artery (B). The plan for ductal stenting was aborted. MRI, magnetic resonance imaging.

Multicenter data aggregation allows participating centers to amass enough patients to study demographics, practice patterns, and analyze outcomes in a manner which would be impossible using only single-center data. ${ }^{19,22}$ Ultimately, large clinical registries should inform quality improvement to drive improvement in outcomes. Using this model for quality improvement, PC4 has recently launched its first

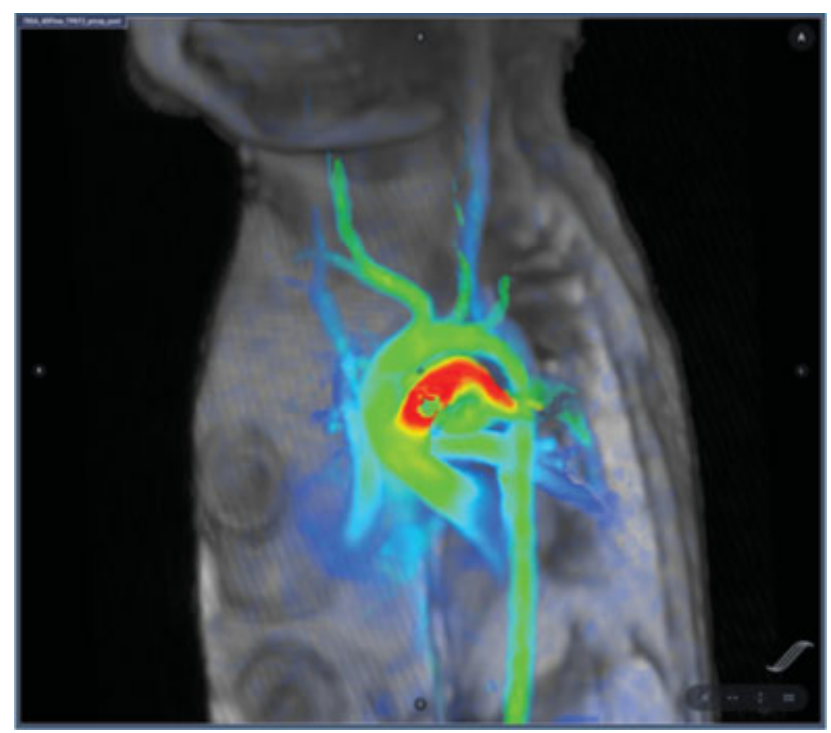

Fig. 4 Four-dimensional phase contrast velocity-encoded (“4D flow”) imaging in a 7-kg infant with an atrial septal defect and partial anomalous pulmonary venous return. Flow analysis can be used to quantify pulmonary-to-systemic flow ratio, differential pulmonary blood flow, valvar insufficiency, stenosis gradient, and other hemodynamic measurements. multicenter quality improvement initiative to reduce cardiac arrests in patients in the CICU. The project is a multiinstitutional study based on aggregate PC4 data using an evidence-based and empirically derived care bundle. ${ }^{23}$ Although data are still being collected and analyzed, early analyses indicate important reductions in cardiac arrest rates. Studies and quality improvement efforts such as these will improve outcomes, spread change, and improve our collective understanding of this complex patient population.

While large registries provide exceptional opportunities for understanding demographics and outcomes, single-center quality improvement remains an important strategy to improve outcomes locally. Successes from implementing this approach have been seen in improving and sustaining handoff processes between the cardiovascular operating room and $\mathrm{CICU}$, where performance improvement methodology and key drivers developed with input from many disciplines allowed clinical staff to improve communication, technology, and information transfer and sustain a shared mental model related to the patients' clinical condition and plan of care. ${ }^{24}$

Translating scientific discovery and advances in clinical care to optimize care for both long- and short-term outcomes requires a coordinated effort by multiple stakeholders. ${ }^{25} \mathrm{~A}$ recent expansion of databases and registries has created a necessity to streamline data collection, analytics, and outcomes reporting to simplify research, quality improvement, and patient advocacy. Cardiac Networks United ${ }^{25}$ has been launched to integrate pediatric and congenital cardiovascular research and quality improvement networks and databases. This will allow researchers to link practices and outcomes across the lifespan for congenital heart patients as well as allow clinical providers to integrate new findings 


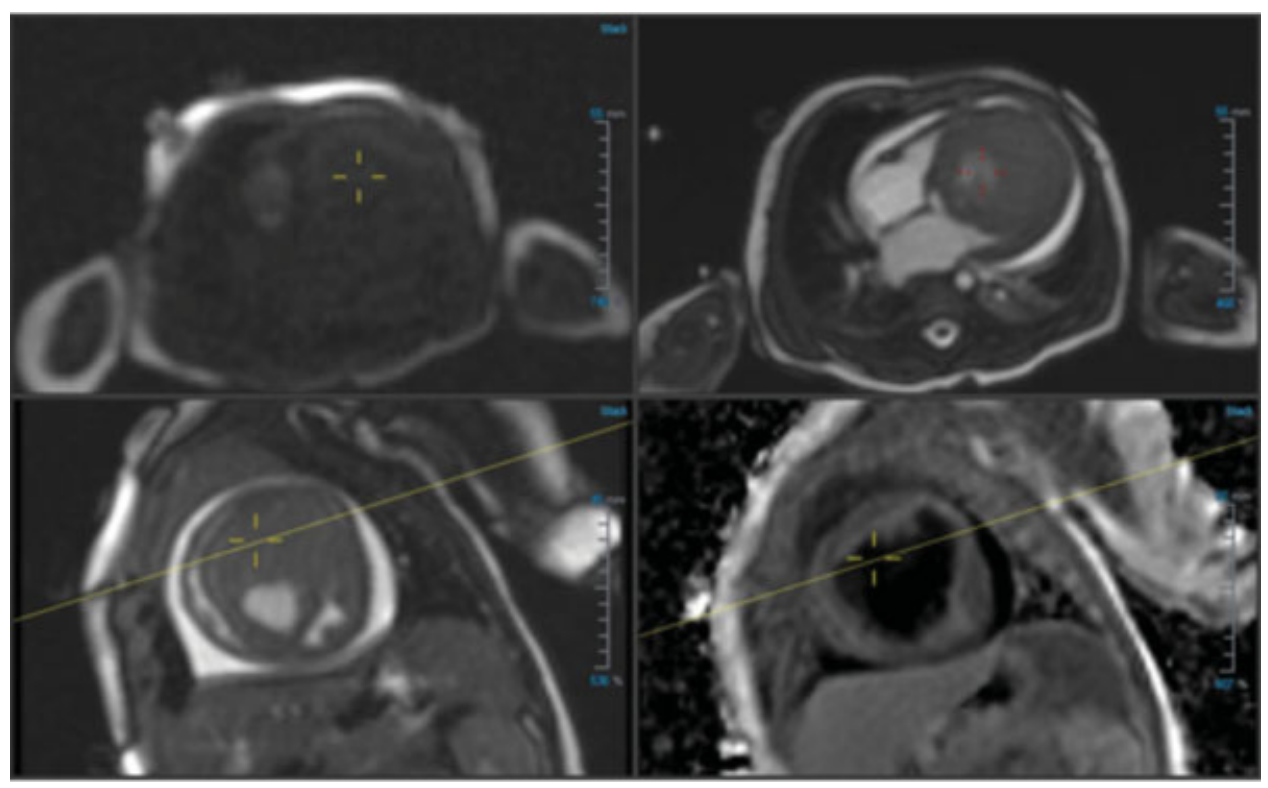

Fig. 5 Cardiac MRI in a 5 kg, 2 months old with a cardiac mass. Cardiac MRI provided information regarding tissue characterization (perfusion, gadolinium enhancement, lipid content, T1 and T2-weighting) suggesting a diagnosis of fibroma. MRI, magnetic resonance imaging.

and lessons learned from both research as well as focused quality improvement networks. Through the evolution of efforts such as Cardiac Networks United, multicenter quality improvement and data sharing will continue to advance the care of children with critical CHD.

Conflict of Interest

None declared.

\section{References}

1 Hoffman JI, Kaplan S. The incidence of congenital heart disease. J Am Coll Cardiol 2002;39(12):1890-1900

2 Raissadati A, Nieminen H, Haukka J, Sairanen H, Jokinen E. Late causes of death after pediatric cardiac surgery: a 60 -year population-based study. J Am Coll Cardiol 2016;68(05):487-498

3 Petrini J, Damus K, Damus R. Trends in Infant Mortality Attributable to Birth Defects-United States, 1980-1995. Morbidity and Mortality Weekly Report (MMWR). Available at: https://www. cdc.gov/mmwr/preview/mmwrhtml/00054921.htm. Accessed May 14, 2019

4 Mahle WT, Newburger JW, Matherne GP, et al; American Heart Association Congenital Heart Defects Committee of the Council on Cardiovascular Disease in the Young, Council on Cardiovascular Nursing, and Interdisciplinary Council on Quality of Care and Outcomes Research; American Academy of Pediatrics Section on Cardiology And Cardiac Surgery; Committee On Fetus And Newborn. Role of pulse oximetry in examining newborns for congenital heart disease: a scientific statement from the AHA and AAP. Pediatrics 2009;124(02):823-836

5 Oster ME, Lee KA, Honein MA, Riehle-Colarusso T, Shin M, Correa A. Temporal trends in survival among infants with critical congenital heart defects. Pediatrics 2013;131(05):e1502-e1508

6 Eckersley L, Sadler L, Parry E, Finucane K, Gentles TL. Timing of diagnosis affects mortality in critical congenital heart disease. Arch Dis Child 2016;101(06):516-520

7 Gardiner HM, Kovacevic A, van der Heijden LB, et al. Prenatal screening for major congenital heart disease: assessing performance by combining national cardiac audit with maternity data. Heart 2014;100(05):375-382
8 Plana MN, Zamora J, Suresh G, Fernandez-Pineda L, Thangaratinam S, Ewer AK. Pulse oximetry screening for critical congenital heart defects. Cochrane Database Syst Rev 2018;3:CD011912

9 Glidewell J, Grosse SD, Riehle-ColarussoT, et al. Actions in support of newborn screening for critical congenital heart disease - United States, 2011-2018. MMWR Morb Mortal Wkly Rep 2019;68(05): 107-111

10 Abouk R, Grosse SD, Ailes EC, Oster ME. Association of US state implementation of newborn screening policies for critical congenital heart disease with early infant cardiac deaths. JAMA 2017; 318(21):2111-2118

11 Kellenberger CJ, Yoo S-J, Büchel ER. Cardiovascular MR imaging in neonates and infants with congenital heart disease. Radiographics 2007;27(01):5-18

12 Tsai-Goodman B, Geva T, Odegard KC, Sena LM, Powell AJ. Clinical role, accuracy, and technical aspects of cardiovascular magnetic resonance imaging in infants. Am J Cardiol 2004;94(01):69-74

13 Puranik R, Muthurangu V, Celermajer DS, Taylor AM. Congenital heart disease and multi-modality imaging. Heart Lung Circ 2010; 19(03):133-144

14 Fratz S, Chung T, Greil GF, et al. Guidelines and protocols for cardiovascular magnetic resonance in children and adults with congenital heart disease: SCMR expert consensus group on congenital heart disease. J Cardiovasc Magn Reson 2013;15:51

15 Taylor AJ, Cerqueira M, Hodgson JM, et al; American College of Cardiology Foundation Appropriate Use Criteria Task Force; Society of Cardiovascular Computed Tomography; American College of Radiology; American Heart Association; American Society of Echocardiography; American Society of Nuclear Cardiology; North American Society for Cardiovascular Imaging; Society for Cardiovascular Angiography and Interventions; Society for Cardiovascular Magnetic Resonance. ACCF/SCCT/ACR/AHA/ASE/ASNC/NASCI/SCAI/SCMR 2010 Appropriate Use Criteria for Cardiac Computed Tomography. A Report of the American College of Cardiology Foundation Appropriate Use Criteria Task Force, the Society of Cardiovascular Computed Tomography, the American College of Radiology, the American Heart Association, the American Society of Echocardiography, the American Society of Nuclear Cardiology, the North American Society for Cardiovascular Imaging, the Society for Cardiovascular Angiography and Interventions, and the Society for Cardiovascular Magnetic Resonance.J Cardiovasc Comput Tomogr 2010;4(06):407.e1-407.e33 
16 Valsangiacomo Buechel ER, Grosse-Wortmann L, Fratz S, et al; EACVI. Indications for cardiovascular magnetic resonance in children with congenital and acquired heart disease: an expert consensus paper of the Imaging Working Group of the AEPC and the Cardiovascular Magnetic Resonance Section of the EACVI. Eur Heart J Cardiovasc Imaging 2015;16(03):281-297

17 Sarikouch S, Schaeffler R, Körperich H, Dongas A, Haas NA, Beerbaum P. Cardiovascular magnetic resonance imaging for intensive care infants: safe and effective? Pediatr Cardiol 2009; 30(02):146-152

18 Windram J, Grosse-Wortmann L, Shariat M, Greer M-L, Crawford MW, Yoo S-J. Cardiovascular MRI without sedation or general anesthesia using a feed-and-sleep technique in neonates and infants. Pediatr Radiol 2012;42(02):183-187

19 Gaies M, Cooper DS, Tabbutt S, et al. Collaborative quality improvement in the cardiac intensive care unit: development of the Paediatric Cardiac Critical Care Consortium (PC4). Cardiol Young 2015;25(05):951-957

20 Anderson JB, Brown DW, Lihn S, et al. Power of a learning network in congenital heart disease. World J Pediatr Congenit Heart Surg 2019;10(01):66-71
21 Brunetti MA, Gaynor JW, Retzloff LB, et al. Characteristics, risk factors, and outcomes of extracorporeal membrane oxygenation use in pediatric cardiac ICUs: a report from the Pediatric Cardiac Critical Care Consortium Registry. Pediatr Crit Care Med 2018;19 (06):544-552

22 Clauss SB, Anderson JB, Lannon C, et al. Quality improvement through collaboration: the National Pediatric Quality Improvement Collaborative initiative. Curr Opin Pediatr 2015;27(05): 555-562

23 Alten JA, Klugman D, Raymond TT, et al. Epidemiology and outcomes of cardiac arrest in pediatric cardiac ICUs. Pediatr Crit Care Med 2017;18(10):935-943

24 Riley CM, Merritt AD, Mize JM, Schuette JJ, Berger JT. Assuring sustainable gains in interdisciplinary performance improvement: creating a shared mental model during operating room to cardiac ICU handoff. Pediatr Crit Care Med 2017;18(09):863-868

25 Gaies M, Anderson J, Kipps A, et al; Cardiac Networks United Executive Committee and Advisory Board. Cardiac Networks United: an integrated paediatric and congenital cardiovascular research and improvement network. Cardiol Young 2018; (December):1-8 